\title{
Mostrar o Brasil e suas populações! Esta é a tarefa sobre a qual tenho me debruçado por longos anos
}

\author{
Por Paula Saldanha*
}

Resumo: Neste depoimento, a jornalista Paula Saldanha conta como seu trabalho de autora e ilustradora de livros para crianças e jovens levou-a a atuar na televisão, em programas como Fantástico, telejornal Hoje e Globinho - primeiro telejornal para crianças e jovens da TV brasileira que marcou toda uma geração. Idealizando o trabalho independente, passou a produzir reportagens especiais, viajando por todo o Brasil, gravando grandes reportagens sobre questões ambientais, especialidade de sua produtora, a RW Cine, responsável pelo renomado projeto Expedições - coroamento de todo o trabalho independente para televisão: documentação do Brasil, suas populações e divulgação nas TVs públicas - TV Brasil e TV Cultura.

Palavras-chave: televisão, história, Globinho, ecologia, meio ambiente.
Abstract: in this testimony, the journalist Paula Saldanha tells us how her work of author and illustrator of books for kids and teens took her to television, acting in programs as Fantástico, Hoje and Globinho - first news program for children and teenagers in Brazilian television that has marked all of a generation. Idealizing an independent work, she started to produce special reports, traveling around Brazil. Long reports on environmental issues are the specialty of her production company - RW Cine - responsible for the reputed project Expedições - that rewarded all her independent work for television with the documentation of this country and its regional populations, and divulgation in public televisions: TV Brasil and TV Cultura.

Keywords: television, history, Globinho, ecology, environment.

Nasci no Rio de Janeiro e desde pequena sou fascinada pelo fenômeno da educação e pelo mundo da literatura. Assistia à luta e ao trabalho que Regina Yolanda, minha mãe, desenvolvia em escolas públicas, fundamentado na expressão criadora.

Antes dos 9 anos já folheava os chamados livros de adulto e tinha a mania de ler enciclopédias e jornais. Aos 13 comecei a fazer gravuras em madeira e

Recebido: $28 / 12 / 2007$ Aprovado: 17/02/2008

* Colaboração de Consuelo Ivo, jornalista especializada em Gestão da Comunicação e editora executiva da revista Comunicação \& Educação. 
1. Os primeiros livros de Paula Saldanha ainda não foram reeditados, mas atualmente ela tem livros publicados em três editoras, para crianças jovens: O Praça Quinze (Ed. José Olympio); Heróis dos Gerais, Balbino em Chamas e Eldorado Garimpo Coragem (Ed. FTD); As Amazônias, Os Pantanais, Mata Atlântica e Os Cerrados (Ediouro) livros de imagens e texto compacto sobre os diferentes biomas do Brasil Um Sonho na Amazônia, Terra do Descobrimento e Quilombo de Frechal (Ediouro) - com personagens adolescentes redescobrindo a vida em suas comunidades. metal, vendendo e expondo alguns trabalhos. Imaginava uma carreira como professora e artista plástica.

Quando completei 18 anos, a editora Primor-Larousse resolveu publicar meu primeiro livro - Tuc-Tuc -, a partir de uma história que escrevi e ilustrei aos 16, para minha mãe utilizar em sala de aula. O livro foi vertido para o inglês, com 20 mil exemplares exportados para a Europa.

Publiquei uma série de livros, ilustrei obras de outros autores, participei de Bienais e Feiras de Livros na Europa, mas nunca havia pensado numa carreira ligada à comunicação. Escrevia artigos para revistas especializadas de educação e literatura.

A idéia de uma escola livre, dinâmica, do maternal à universidade, estava firme na minha cabeça, e resolvi me formar em Pedagogia pela UFRJ - Universidade Federal do Rio de Janeiro (1972-1977). Todo meu trabalho em diversas escolas tinha como base a literatura em salas de aula.

\section{A TELEVISÃO}

Ainda em 1974, logo depois do nascimento de minha filha Gabriela Werneck (hoje designer), fui entrevistada para o programa Fantástico, da TV Globo, sobre meu trabalho como autora e ilustradora de livros para crianças e jovens ${ }^{1}$.

Após a matéria ir ao ar, os diretores me convidaram para apresentar o programa, sem eu jamais ter pensado em trabalhar em televisão. Aos 20 anos, casada e com uma filha, eu nem sequer tinha televisão!

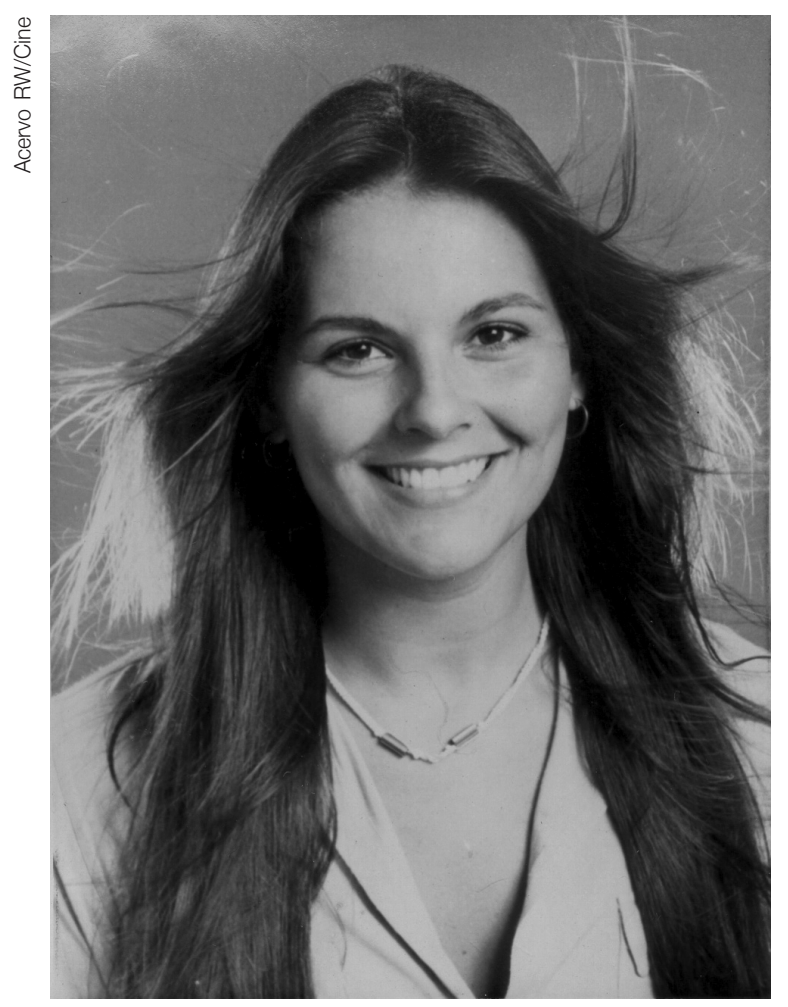

A ida para a televisão na década de 1970 possibilitaria um diálogo maior com o público juvenil. 
Mas que fenômeno fabuloso este da televisão! Descobri que, em lugar de dar meu recado para milhares de jovens, como era o caso dos livros e das escolas, passei a me comunicar com milhões de pessoas instantaneamente.

Na determinação do governo da ditadura militar estava a implantação de um fabuloso e eficiente sistema de telecomunicações, alcançando todo o território nacional. Hoje, a televisão do Brasil é das mais eficientes do mundo. O objetivo do regime de exceção era passar informações controladas para as massas. Mas o poder da televisão foi maior. Assim como na educação, a função conservadora foi atropelada pelo papel dinâmico da informação, que passou a alimentar toda uma população, sem acesso a livros e a boas escolas.

Resolvi, então, me dedicar a este veículo poderoso produzindo, a partir de 1976, uma sessão de literatura e reportagens sobre assuntos infanto-juvenis no telejornal Hoje. Já com o registro de jornalista (por tempo de serviço), passei a me dedicar à área de comunicação.

Em 1977, comecei a apresentar e fazer reportagens para o Globinho, telejornal para crianças e jovens que marcou toda uma geração. Para mim, foi um maravilhoso laboratório em que levei adiante minhas experiências de educadora e escritora - dessa vez, na nova mídia, a televisão.

\section{GLOBINHO - PRIMEIRO TELEJORNAL PARA CRIANÇAS E JOVENS DA TV BRASILEIRA}

Todas as sessões que criamos no Globinho - meio ambiente, música, literatura, artes plásticas - continham um pouco de trabalho jornalístico e de minha experiência nas outras áreas. Preparávamos a pauta e, inicialmente, eu fazia todas as reportagens, para colocar o jornal no ar diariamente.

A mistura de informação com entretenimento era realizada com filmes de animação e desenhos animados de vanguarda. Os filmes não eram comerciais, mas escolhidos a dedo, entre as melhores produções da Europa.

O diferencial desse telejornal era dado pelos editoriais e pelas reportagens, com foco na criança, no jovem - enfim, tudo era pensado para as novas gerações. A linguagem também era bem cuidada, mas nunca simplificada. Como apresentávamos os assuntos da atualidade (abordados nos outros telejornais), tínhamos que conhecer os temas a fundo, para trocar em miúdos. Mas o Globinho ia além. Explicávamos, por exemplo, a indústria da seca no Nordeste, anistia política, eleições diretas e a Declaração Universal dos Direitos Humanos - temas proibidos na época da ditadura militar.

$\mathrm{Na}$ época, segundo o Ibope, $50 \%$ da audiência era de crianças e $50 \%$, de adultos - gente com mais de 18 anos. Um público bem diversificado, em todo o País, que garantia ao Globinho recordes de audiência, sempre. Acredito que, em época de ditadura militar, o programa era um dos mais engajados do telejornalismo - exatamente porque não tinha censura prévia. 


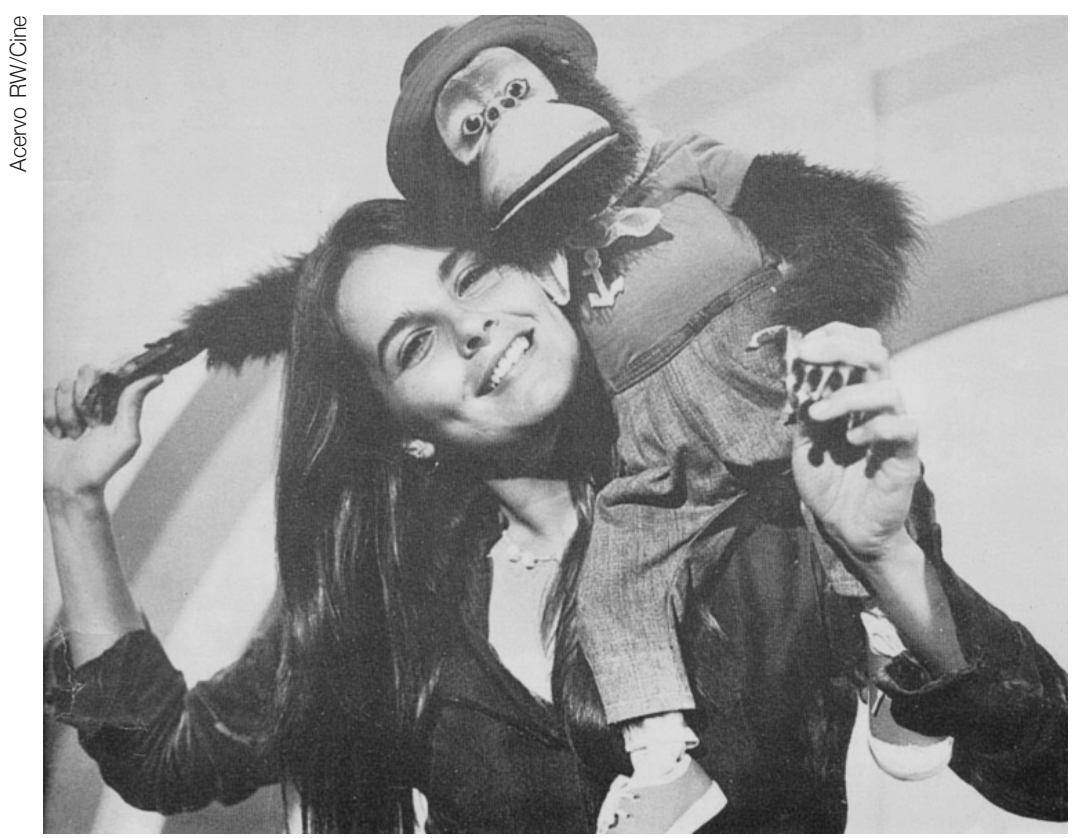

Com um de seus "companheiros" de cenário da TV Globinho. Encanto e criação de uma linguagem que marcou toda uma geração.

\section{SESSÃO DE LITERATURA INFANTO-JUVENIL, DE 1976 A 1985}

Dando continuidade ao trabalho iniciado em 1976 no Jornal Hoje (produzido até 1985), mantive a Sessão de Literatura nos anos em que fiz o Globinho. Quando saía de férias, deixava várias matérias gravadas, para não haver interrupção. Longas entrevistas com Jorge Amado, Ziraldo e Ana Maria Machado são apenas alguns exemplos. Os dez anos contínuos desta sessão de literatura infanto-juvenil na TV foram tema de minha apresentação no Congresso do IBBY/Unesco em Oslo, em 1986.

\section{CLUBES DE LEITURA, CONCURSOS DE LITERATURA E MINIBIBLIOTECAS}

Num país sem tradição de leitura, os Concursos de Literatura, as Minibibliotecas e os Clubes de Leitura que ajudamos a criar em todo o Brasil fizeram do Globinho o campeão de cartas do público, em toda a TV Globo.

As Minibibliotecas Globinho foram criadas e distribuídas entre 1977 e 1983. Desde o início de meu trabalho, foram formadas mais de cem Minibibliotecas Globinho, com o melhor da literatura infanto-juvenil, para doação a comunidades de baixa renda. Além das doações, o telejornal apresentava reportagens com os jovens autores e leitores. Centenas de clubes de leitura começaram a surgir e funcionar por longos anos, em várias partes do Brasil, incentivados pelo debate literário no Globinho. 


\section{PRODUÇÃO INDEPENDENTE}

Além do trabalho na TV Globo, fundei com meu marido, o biólogo Roberto Werneck, a produtora $R W \operatorname{Cine}^{2}$, especializada em documentários científicos (1977).

Em março de 1979, já havia criado e dirigido o Globinho Repórter, primeiro programa de Ecologia da TV brasileira. Diversos documentários nossos, produzidos de forma independente, alimentaram este programa, exibido na Globo, aos sábados, ao meio-dia. Muitos temas nacionais de hoje - destruição da Amazônia, da Mata Atlântica e de nossos recursos hídricos - já eram pautados no programa.

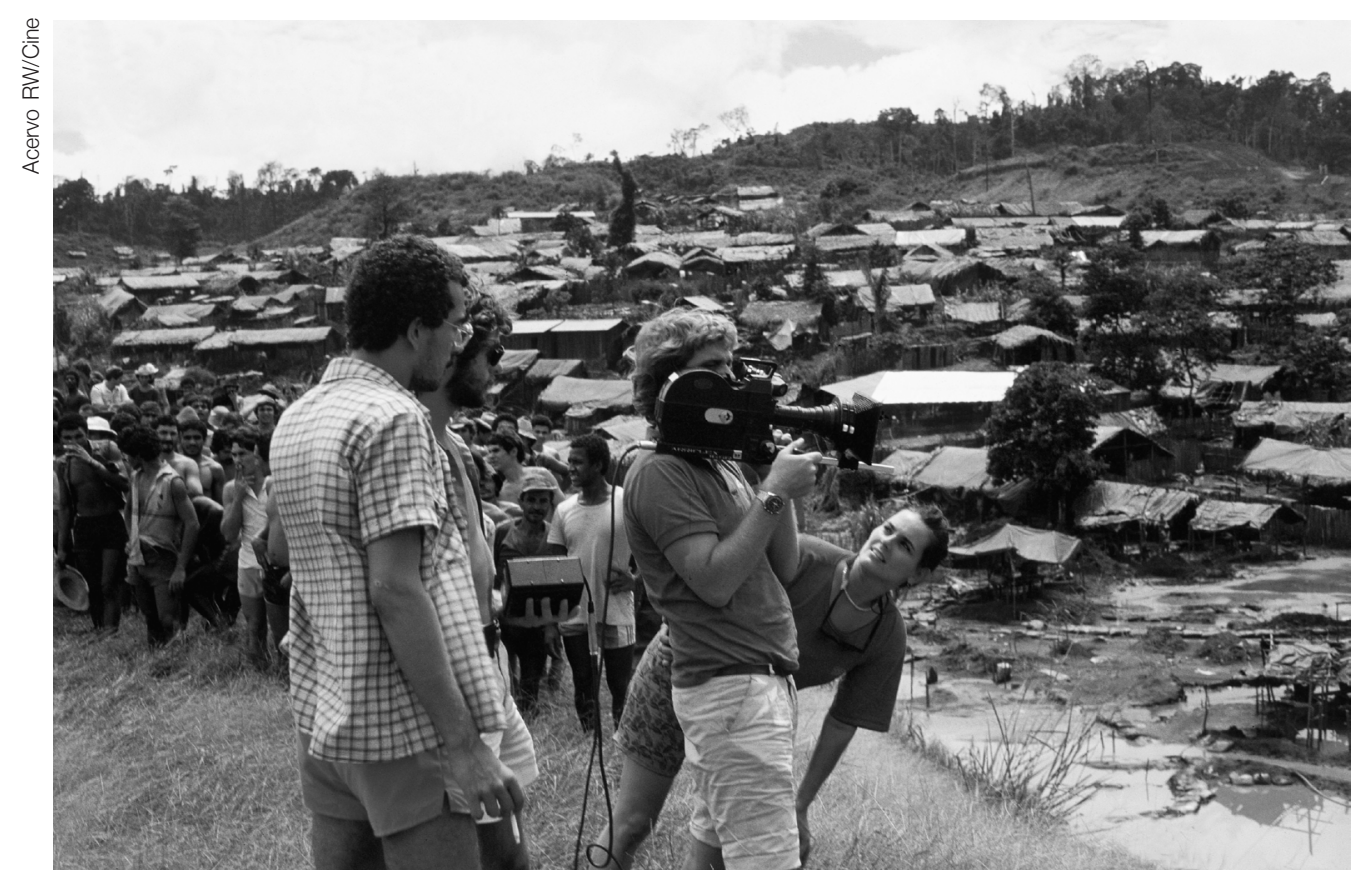

Paula Saldanha, o companheiro Roberto Werneck e sua equipe em Serra Pelada, 1983.

Por problemas ligados à censura da ditadura militar, alguns documentários, como A Amazônia é Nossa, As Lagoas Estão Desaparecendo e Doenças Tropicais, tiveram cortes de conteúdo, numa época em que as questões ambientais eram consideradas subversivas. O Globinho Repórter durou apenas um ano.

Em 1985, após o término do Globinho, de novas participações minhas no Jornal Hoje e de novas apresentações do Fantástico, percebi que muitos de meus projetos planejados para a TV não poderiam ser realizados. Não queria ser apenas apresentadora. Pedi então meu desligamento como funcionária da emissora.

\section{REPORTAGENS INDEPENDENTES PARA O FANTÁSTICO}

Sempre busquei liberdade de expressão. Minha trajetória na TV tinha um objetivo: dar o meu recado.

2. Disponível em: <http:// www.expedicoes.tv $>$. 
Em 1987 propus à TV Globo a produção independente de reportagens especiais para o Fantástico. Eu e o Roberto viajávamos por todo o Brasil, gravando grandes reportagens sobre questões ambientais - especialidade de nossa produtora. A vida selvagem e as paisagens espetaculares de nosso país passaram a chegar para o grande público.

Questões polêmicas começavam a surgir discretamente, já que estávamos em período de abertura política: grilagem de terras, com expulsão de trabalhadores do campo, queimadas na Amazônia etc. O desmatamento da Amazônia, aliás, era tema constante e já podíamos dizer: a Amazônia é nossa! As reportagens para o Fantástico, exibidas até maio de 1992, foram uma verdadeira escola para nossa equipe, já que a direção do programa queria belas matérias, de todas as partes do País, em um curto espaço de tempo. Com orientação da emissora, essas reportagens mesclavam as informações científicas, do gênero documentário, com reportagens irreverentes e dinâmicas, ilustradas por espetaculares shows de imagens, para o grande público. Numa época em que ecologia ainda era considerada coisa de esquerda, quando ainda não chegavam aqui as produções da National Geographic e da Discovery, essas reportagens do Fantástico faziam denúncias, mas também apresentavam imagens espetaculares de nosso vasto e desconhecido território.

\section{MEIO AMBIENTE}

Entretanto, desde 1972, quando eu e o Roberto iniciamos nosso projeto de vida e trabalho, já acompanhávamos de perto os movimentos ambientalistas na Europa e nos Estados Unidos. Em 1974, quando fui convidada a trabalhar na televisão, levei minhas preocupações com o que estava acontecendo em nosso País, em termos de destruição dos ecossistemas, dos recursos naturais e da qualidade de vida das populações.

A questão do aquecimento global, que só agora ganhou destaque na mídia, já tinha sido levantada em reportagens independentes nossas para o Fantástico, como Desertos da Amazônia. Pesquisadores do INPE - Instituto Nacional de Pesquisas Espaciais, já falavam de aumento do gás carbônico na atmosfera e da elevação do nível dos mares - isso há vinte anos!

Tenho acompanhado, há trinta anos, as questões ambientais em nosso país, que tem (desde 1988) uma das legislações ambientais mais avançadas do mundo. Muita coisa está melhor, menos o cuidado com os recursos hídricos e com a floresta Amazônica.

Por conta deste trabalho, voltado para a área de meio ambiente, participei de diversos congressos no Brasil e no exterior, incluindo relatos de experiência, em conferências da Organização dos Estados Americanos (OEA).

A convite do Governo brasileiro, produzi para a Rio 92 (Conferência da ONU para Meio Ambiente e Desenvolvimento - Rio Centro) documentários e exposições bilíngües com nosso acervo, para os chefes de Estado de mais de 150 países. 
Inspirada em meu programa, Terra Azul, na Rede Manchete (1989-1990), criei e comecei a presidir, em 1991, a ONG Terra Azul, reconhecida como Instituição de Utilidade Pública, tendo como sociofundadores grandes nomes de nossa cultura, como Darcy Ribeiro e Oscar Niemeyer. Desde 2006, a ONG recebeu o nome de Instituto Paula Saldanha.

\section{O PROJETO EXPEDIÇÕES}

Há doze anos realizo, com meu companheiro Roberto, o Projeto Expedições ${ }^{3}$ - coroamento de todo o trabalho independente para televisão: documentação do Brasil, suas populações e divulgação nas TVs públicas - TV Brasil e TV Cultura.

Na televisão, a série é exibida semanalmente, com programas de $30 \mathrm{mi}$ nutos de duração. Para isso, duas equipes precisam viajar constantemente por diversas partes do País, trazendo documentários temáticos, em que tudo é ilustrado por reportagens e imagens. Como o nome mesmo diz, Expedições não é um programa feito em estúdio, mas sim gravado $99 \%$ em campo.

Desde 1993, Pedro Werneck, meu filho do meio (hoje documentarista), passou a apoiar nossa equipe em campo e, em 2002, assumiu a direção do programa Expedições e da RW Cine.

\section{AS VIAGENS}

Mostrar o Brasil e suas populações! Esta é a tarefa sobre a qual tenho me debruçado por longos anos. Além das questões geográficas, ambientais, étnicas e culturais, os documentários da série Expedições abordam arqueologia, paleontologia, geologia e história.

$\mathrm{Na}$ documentação de grupos indígenas e outras populações tradicionais, tentamos intervir o mínimo possível, a começar pelo respeito e cuidado na

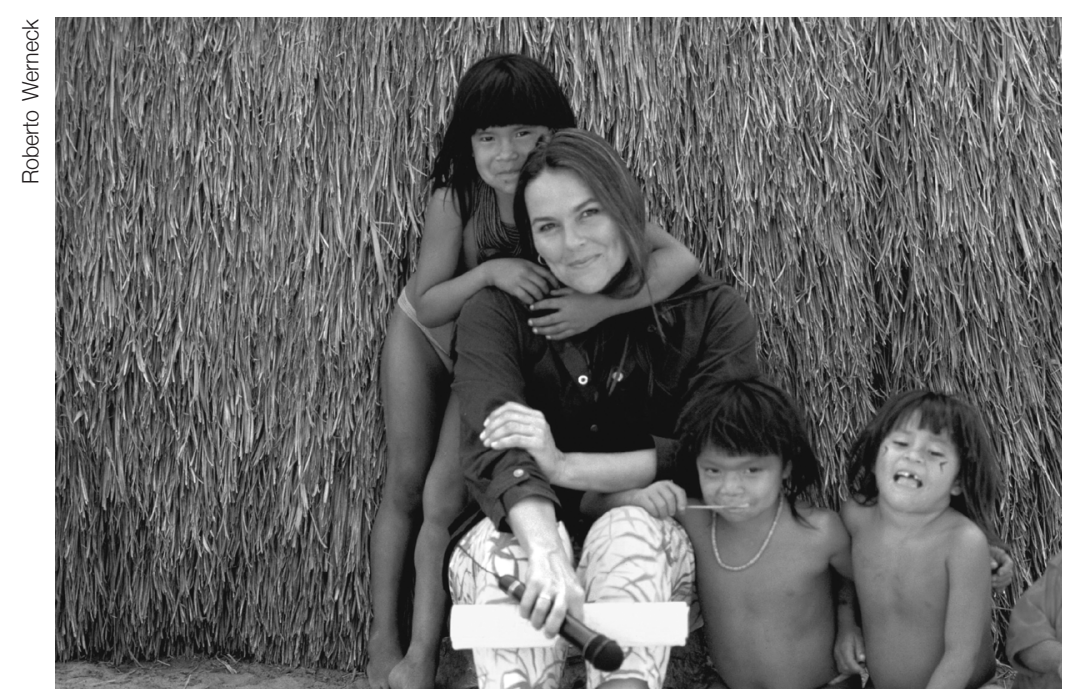

3. Disponível em: <http:// www.expedicoes.tv> 
entrada em comunidades ou aldeias. Em geral, sempre fomos convidados pelas lideranças e acolhidos carinhosamente, para realizar um trabalho de documentação, divulgação e, principalmente, valorização da cultura de cada região e população.

Em geral o trabalho é tranqüilo na maior parte das comunidades. Mas, em aldeias indígenas com quase nenhum contato com o chamado homem branco, existe sim um grande choque cultural. Cito, como exemplo, a nossa chegada a uma aldeia Yanomami, em Parafuri (Roraima), que estava em guerra com um grupo vizinho. Apesar de sabermos que índios pintados de preto estão em conflito, não notamos a situação de perigo. No entanto, após toda a gritaria dos índios na confusão de nossa chegada no helicóptero da Fundação Nacional de Saúde, todas as pessoas na aldeia foram gentis.

A maior parte das expedições acontece fora das cidades e das estradas. Para chegarmos a lugares de difícil acesso, utilizamos canoas, voadeiras, carros com tração 4 x 4, pequenos aviões e helicópteros. É perigoso levar muito peso em helicópteros ou aviões. Carregamos o mínimo possível de roupas e acessórios, porque não podemos abrir mão dos equipamentos - em geral, duas ou três câmeras de vídeo, duas máquinas fotográficas, baterias, fitas etc.

Uma das maiores dificuldades é colocar uma equipe de quatro pessoas e muito equipamento em um helicóptero, avião pequeno ou canoa. Às vezes temos que dividir a equipe.

O mau tempo é um grande inimigo das produções de campo. Não apenas por prejudicar as gravações de imagens, mas principalmente pelo perigo dos sobrevôos.

Voar sempre tem riscos. Voar na Amazônia, em tempo de chuvas, sobre a imensidão de floresta compacta, é muito mais difícil. Já tivemos que fazer pousos forçados, aterrissando até numa estrada no Acre, torcendo para não passar nenhum caminhão.

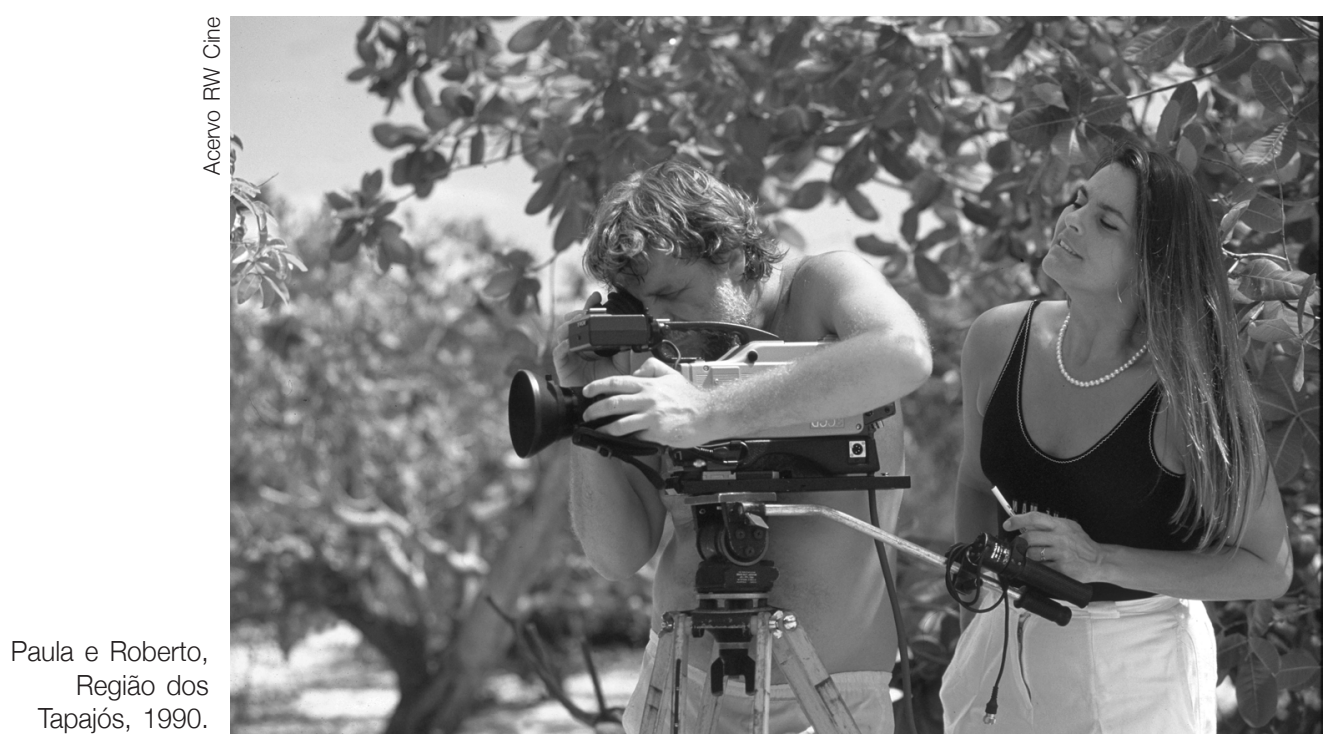


Nosso grande objetivo nas expedições é sempre captar, documentar o máximo, da melhor forma possível, as regiões e suas populações. Para isso, permanecemos mais tempo nos locais. É mais fácil fazer viagens longas quando se é independente.

Como gravamos e fotografamos para nosso próprio Acervo de imagens, quanto mais riqueza na documentação, melhor.

Muitas vezes, temos que abrir mão de conforto e, até mesmo, dormir ao relento. É comum passarmos dias a água e bolacha, gravando até o pôr-do-sol, para não perder a luz. Dependendo da região, a alimentação é à base de farinha e peixe fresco, preparado na fogueira improvisada, junto ao acampamento.

Existem cuidados que devem ser tomados com a questão das doenças, principalmente transmitidas por água contaminada e insetos. Quase sempre levamos água mineral ou consumimos água de nascente segura.

Sempre nos protegemos da cabeça aos pés, de manhã cedo e ao entardecer, que são os horários mais perigosos. Apesar do calor sufocante, somos obrigados a vestir calças, meias grossas e blusas de manga comprida. O grande temor na floresta amazônica não é de cobras ou onças, mas sim do mosquito, principalmente por causa da malária.

\section{OUTRAS MÍDIAS}

Com o material produzido para o programa Expedições na TV, realizamos também exposições multimídia e publicamos 22 livros ${ }^{4}$.

A idéia de lançar os documentários Expedições em DVDs era um sonho nosso. Só assim as pessoas podem ter o chamado cinema em casa. Iniciamos a coletânea de DVDs com a maior região do Brasil - a Amazônia. Cada volume traz seis documentários em três DVDs trilíngües.

Escolhi as produções que representam, de forma mais abrangente e atual, o que está acontecendo nessa imensa região. No volume II, mostramos o que ocorre na Amazônia, sob a visão dos pesquisadores. No documentário Arco do Desflorestamento, divulgamos dados impressionantes: $80 \%$ das derrubadas e queimadas da região se destinam à produção de carne e soja para exportação. $\mathrm{O}$ Brasil está entre $4^{\circ}$ e $5^{\circ}$ lugar entre os países que mais emitem carbono para atmosfera, principalmente $(75 \%)$ por causa de queimadas. Por outro lado, nunca se pesquisou tanto sobre a região. Instituições científicas como INPA, Museu Goeldi, INPE, COPPE, entre outras tantas, estão trabalhando juntas no grande programa de pesquisas Piatam, que está traçando novos rumos para a Amazônia. São vários os assuntos, e sempre fascinantes.

Além da distribuição para videotecas de universidades e instituições de pesquisa, os DVDs estão seguindo para mais de cem países, através do Itamaraty. O projeto é desenvolvido através da Lei Rouanet, via Ancine, com o patrocínio da Petrobras e apoio do projeto Piatam.
4. Informações sobre as publicações da RW no site <http://www.expedicoes.tv>. 
No projeto dos DVDs, nosso objetivo é abordar, além da Amazônia, os grandes biomas brasileiros - pantanal, caatinga, cerrado, litoral - e aspectos antropológicos e culturais das diversas populações.

\section{O PAPEL DA TELEVISÃO}

É impressionante o papel da televisão nas áreas mais distantes do território brasileiro. Populações que nunca tiveram acesso à informação referente aos cuidados com saúde, alimentação, passaram a ter na TV um aliado no desenvolvimento de suas comunidades.

No meio da floresta amazônica, no Pantanal, ou no sertão do Nordeste, pequenos geradores a óleo diesel são ligados das 6 às 10 horas da noite, na maioria das comunidades que não têm energia elétrica. A programação da TV, captada através de uma antena parabólica, é uma janela que se abre para o mundo.

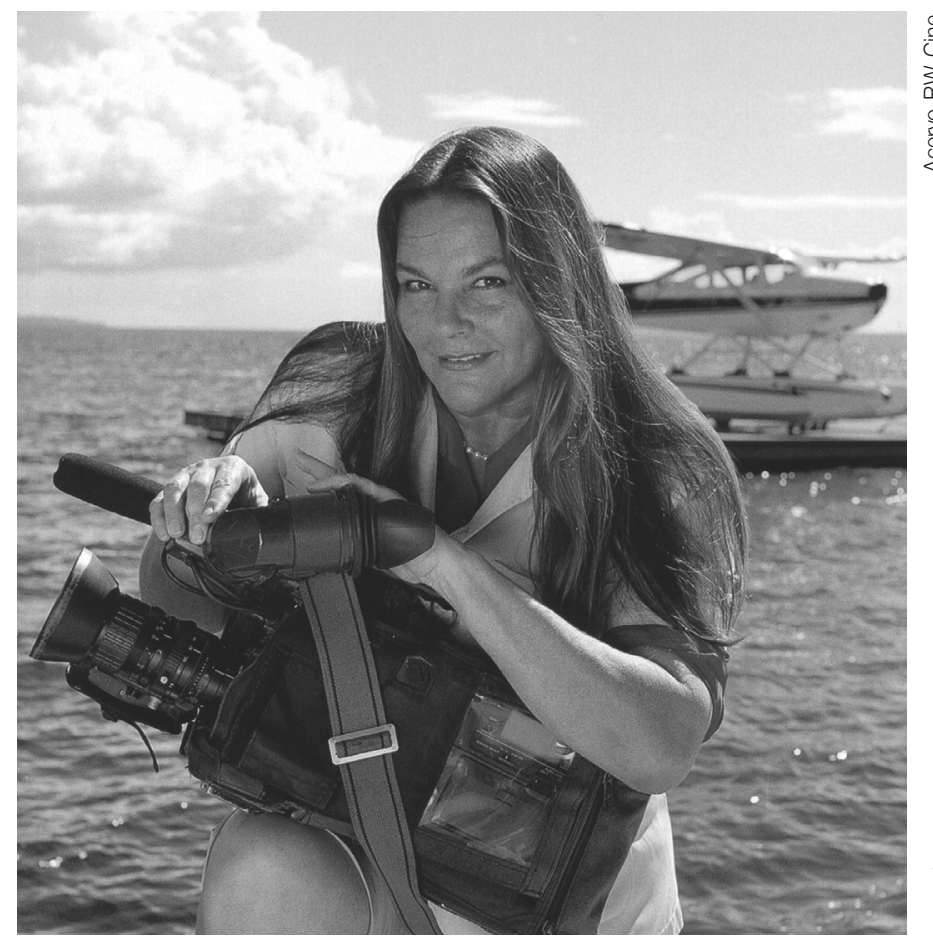

A importância da televisão: informação e entretenimento democráticos.

Em reportagens de garimpos na Amazônia, documentamos as barracas onde vivem os garimpeiros, por anos seguidos. São apenas quatro estacas, com um plástico preto em cima. Mas muitas delas com antena parabólica e TV acionada por gerador.

Em trinta anos de documentação de Brasil, temos notado uma grande diferença na conscientização de homens e mulheres, que lutam por um futuro melhor para seus filhos. Temos visto um número cada vez maior de comunidades se mobilizando para realizar projetos de melhoria de qualidade de vida. 
Esta é a importância da televisão: levar informação e entretenimento, de forma democrática, para todo o povo brasileiro.

\section{A TV PÚBLICA}

Os objetivos de nosso projeto Expedições se afinam com os principais objetivos da TV pública brasileira. Na TVE, agora TV Brasil, sempre divulgamos a riqueza étnica, natural e cultural brasileira, fortalecendo a cultura nacional e regional, dando voz às comunidades de todos os cantos do País.

Acabo de voltar de Brasília, onde participei da comissão que acompanhou a votação da TV pública no Congresso Nacional. Tem sido uma verdadeira luta implantar uma TV pública realmente forte, unificada e eficiente no Brasil, em que sempre se deu apoio às redes de televisão comerciais. O mais grave é que as televisões comerciais passaram o melhor de sua grade de programação para os canais por assinatura - que é a TV paga, fora do alcance da grande maioria do povo brasileiro.

Assistimos, nos últimos anos, ao esvaziamento da programação das TVs abertas comerciais que, com exceção de telejornais e teledramaturgia, sofre um empobrecimento de conteúdos e perda de qualidade jamais vista na história da televisão brasileira.

$\mathrm{Na}$ contramão dessa tendência antidemocrática dos canais comerciais, $T V$ Brasil e TV Cultura reúnem em sua grade de programação alguns dos melhores programas da TV brasileira. Mas ambas não têm o alcance das emissoras comerciais, tanto em audiência como em presença do sinal em todo o território nacional.

O programa Expedições, por exemplo, está entre os que mais têm audiência na TV Brasil (Educativa) e na Cultura, alcançando mais de 10 milhões de telespectadores por semana, nas suas cinco exibições. Mas ainda é pouco, se compararmos a programas das mais fortes TVs comerciais do Brasil, que chegam a 50 milhões de habitantes em uma única exibição.

A criação da Empresa Brasil de Comunicação (EBC), gestora da nova TV Brasil, permitirá a reunião de forças, idéias e tecnologia, para levar riqueza de conteúdos e qualidade de programação a todo o povo brasileiro. Além disso, com a tecnologia digital e, futuramente, com a TV interativa, será possível linkar conteúdos de internet e TV. Só assim teremos a democratização da informação em nosso país.

\section{NOVOS PROJETOS}

Estou preparando, com Roberto e Pedro, um novo projeto para a TV pública brasileira. Trata-se de uma série de programas de conteúdos sobre Brasil e um portal gratuito na internet, alimentados por nosso acervo de trinta anos de documentação de Brasil. 


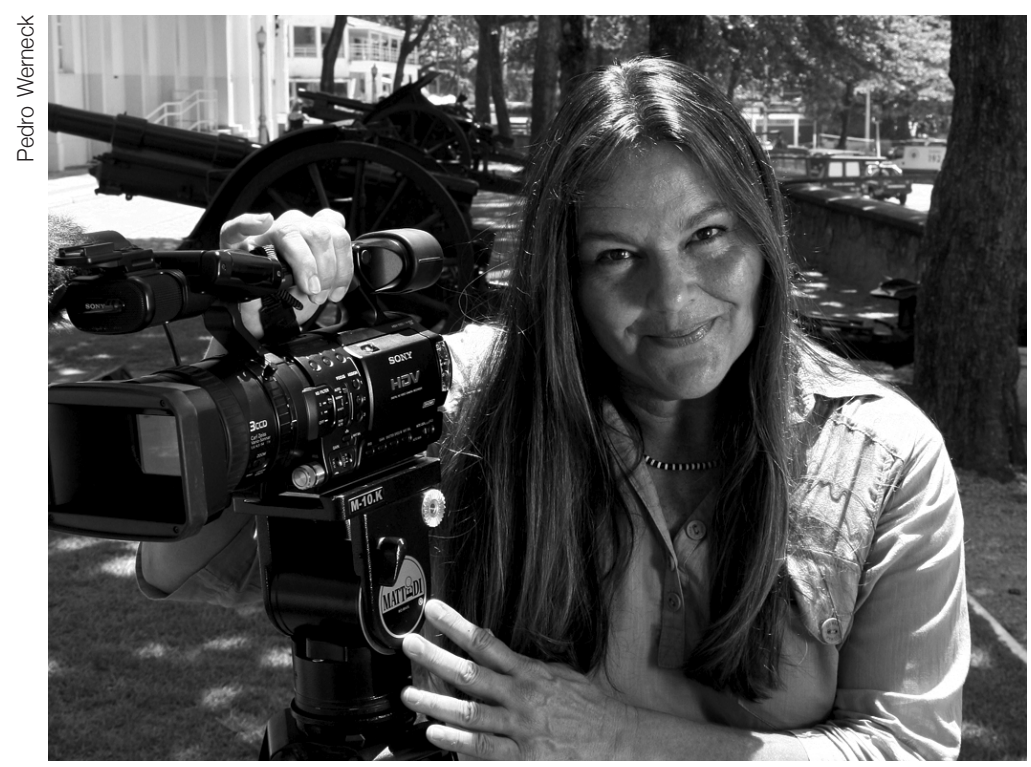

Novos rumos para a TV pública no Brasil.

Foi necessário implementar, em nossa produtora, toda uma parte técnica, para viabilizar os programas da era digital e a informatização de nosso Acervo. Além do que é editado, arquivamos nosso material original, bruto. Por isso temos um grande volume de fotos, fitas de vídeo e filmes, que precisam ser digitalizados. Lucas Werneck, meu filho caçula (que cursou Ciências Exatas), está trabalhando com Pedro nessa empreitada, que viabilizará uma série de novos projetos de conteúdos sobre nosso país e nossa gente. 